ARTICLE

Received 20 Mar 2015 | Accepted 27 Jul 2015 | Published 1 Sep 2015

DOI: $10.1038 /$ ncomms 9177

OPEN

\title{
Electrocatalytic reduction of carbon dioxide to carbon monoxide and methane at an immobilized cobalt protoporphyrin
}

Jing Shen ${ }^{1}$, Ruud Kortlever ${ }^{1}$, Recep Kas ${ }^{2}$, Yuvraj Y. Birdja', Oscar Diaz-Morales ${ }^{1}$, Youngkook Kwon', Isis Ledezma-Yanez ${ }^{1}$, Klaas Jan P. Schouten ${ }^{1}$, Guido Mul $^{2} \&$ Marc T.M. Koper $^{1}$

The electrochemical conversion of carbon dioxide and water into useful products is a major challenge in facilitating a closed carbon cycle. Here we report a cobalt protoporphyrin immobilized on a pyrolytic graphite electrode that reduces carbon dioxide in an aqueous acidic solution at relatively low overpotential $(0.5 \mathrm{~V})$, with an efficiency and selectivity comparable to the best porphyrin-based electrocatalyst in the literature. While carbon monoxide is the main reduction product, we also observe methane as by-product. The results of our detailed $\mathrm{pH}$-dependent studies are explained consistently by a mechanism in which carbon dioxide is activated by the cobalt protoporphyrin through the stabilization of a radical intermediate, which acts as Brønsted base. The basic character of this intermediate explains how the carbon dioxide reduction circumvents a concerted proton-electron transfer mechanism, in contrast to hydrogen evolution. Our results and their mechanistic interpretations suggest strategies for designing improved catalysts.

\footnotetext{
${ }^{1}$ Leiden Institute of Chemistry, Leiden University, PO Box 9502, 2300 RA Leiden, The Netherlands. ${ }^{2}$ PhotoCatalytic Synthesis Group, MESA + Institute for Nanotechnology, Faculty of Science and Technology, University of Twente, Meander 229, PO Box 217, 7500 AE Enschede, The Netherlands. Correspondence and requests for materials should be addressed to M.T.M.K. (email: m.koper@chem.leidenuniv.nl).
} 
T he efficient electrochemical reduction of carbon dioxide to a fuel with a high-energy density would be a major step forward in the introduction of a $\mathrm{CO}_{2}$ neutral energy cycle, as it would allow for the direct low-temperature conversion of photo-generated electrical current to stored chemical energy, in a manner very similar to the way nature stores solar energy. Plants fix $\mathrm{CO}_{2}$ from the atmosphere by photosynthesis in an enzymatic complex called Rubisco, which selectively binds $\mathrm{CO}_{2}$ and inserts it into existing carbon chains by reductive carboxylation. The highenergy electrons necessary for this process are photo-generated by photosystem II.

Synthetic catalysts for the electrocatalytic reduction of $\mathrm{CO}_{2}$, which could facilitate such an artificial $\mathrm{CO}_{2}$ neutral redox cycle, have been studied for many decades ${ }^{1-4}$. A main challenge in electrochemical $\mathrm{CO}_{2}$ reduction is to develop catalysts that are capable of reducing $\mathrm{CO}_{2}$ beyond the two-electron products carbon monoxide $(\mathrm{CO})$, formic acid $(\mathrm{HCOOH})$, and oxalate $\left(\mathrm{C}_{2} \mathrm{O}_{4}^{2-}\right)$. Unfortunately, the formation of reduction products requiring four or more electrons is invariably associated with considerable overpotentials due to the multiple intermediates involved in the reaction mechanisms ${ }^{5}$ (although more reduced products often have higher stability and correspondingly more positive equilibrium potentials). Metallic copper is unique in producing significant amounts of high-energy multi-electron transfer products such as methane, ethylene and ethanol ${ }^{3,6,7}$. Molecular catalysts that are capable of reducing $\mathrm{CO}_{2}$ to a product different from one of the above-mentioned two-electron products are much less common and typically involve a strong interaction with the working electrode ${ }^{8}$. A second important challenge in $\mathrm{CO}_{2}$ electrocatalysis concerns the suppression of the concomitant evolution of hydrogen, which is a dominant side reaction for $\mathrm{CO}_{2}$ reduction from aqueous electrolytes. Strategies for suppressing hydrogen evolution typically involve working with high(er) $\mathrm{CO}_{2}$ to proton ratios, such as high $\mathrm{CO}_{2}$ pressures or solvents with a higher $\mathrm{CO}_{2}$ solubility.

Recent fundamental and theoretical work has reconsidered porphyrin-based molecular catalysts for electrochemical $\mathrm{CO}_{2}$ reduction. Tripkovic et al. ${ }^{9}$ have performed extensive density functional theory calculations of metal-functionalized porphyrinlike graphene surfaces, and predicted the potential formation of methane and methanol from $\mathrm{CO}_{2}$. Costentin et al. ${ }^{10}$ considered ligand modifications of iron-based porphyrins and found that local proton sources built into the porphyrin ring give rise to high activity and good Faradaic efficiency (FE) for the reduction of $\mathrm{CO}_{2}$ to $\mathrm{CO}$ in a mixed DMF-water solvent. In fact, it has been known since the early 1980s that cobalt (Co)-based macrocyclic complexes, either in solution or adsorbed onto carbon electrodes, act as effective electrocatalysts for $\mathrm{CO}_{2}$ reduction, producing $\mathrm{CO}$, $\mathrm{HCOOH}$, methanol and methane, although at relatively high overpotential and with varying selectivity ${ }^{11-15}$.

Herein, we report on the electrochemical reduction of $\mathrm{CO}_{2}$ to $\mathrm{CO}$ and methane, as well as smaller amounts of $\mathrm{HCOOH}$ and methanol, on a simple Co protoporphyrin molecular catalyst immobilized onto a pyrolytic graphite (PG) electrode in a purely aqueous electrolyte solution. Previous similar work using immobilized Co porphyrins or Co phthalocyanines has shown the capability of Co-based catalysts to achieve a high FE towards $\mathrm{CO}$, which is highly sensitive to $\mathrm{pH}$ and potential ${ }^{16-18}$. Our work confirms that immobilized Co-based porphyrins are good $\mathrm{CO}_{2}$ reduction electrocatalysts capable of producing multi-electron products such as methane and methanol. More significantly, our work underscores the important role of $\mathrm{pH}$ in steering the catalytic activity and selectivity towards $\mathrm{CO}$ and $\mathrm{CH}_{4}$, especially in the very narrow $\mathrm{pH}=1-3$ range in the absence of coordinating anions. This high sensitivity to $\mathrm{pH}$ is explained by a mechanism highlighting the important role of the initial electron transfer in activating $\mathrm{CO}_{2}$ electrochemically. We also demonstrate how such a mechanism for $\mathrm{CO}_{2}$ reduction manifests experimentally and how this property can be exploited to suppress concomitant hydrogen evolution. Furthermore, we show that the overpotential and corresponding turnover frequency (TOF) for $\mathrm{CO}_{2}$ reduction of our catalyst compare favourably to the best molecular porphyrinbased catalyst in the literature ${ }^{10}$. Therefore, we believe that these insights may have significant implications for the design of new and improved molecular catalyst electrodes and for the formulation of optimized process conditions for efficient electrochemical $\mathrm{CO}_{2}$ reduction to $\mathrm{CO}$ as well as to products reduced to a more significant degree.

\section{Results}

Voltammetry and online electrochemical mass spectrometry. The Co protoporphyrin-coated PG (CoPP-PG) electrode was prepared following a procedure described earlier ${ }^{19}$ and was detailed in the Methods section. In situ electrochemical scanning tunnelling microscopy and atomic force microscopy images of iron and zinc protoporphyrins on basal plane graphite electrodes by Tao et al. ${ }^{20}$ suggest that these molecules form monolayer films on the electrode with the molecules lying flat. The blank cyclic voltammograms of the PG electrode, the CoPPPG electrode in $0.1 \mathrm{M} \mathrm{HClO}_{4}$ and the voltammetry of the dissolved CoPP in the same electrolyte are compared in Supplementary Fig. 1. The voltammetry in Supplementary Fig. 1 shows the reversible redox peak of the $\mathrm{Co}^{3+} / \mathrm{Co}^{2+}$ transition at $0.8-0.85 \mathrm{~V}$ versus reversible hydrogen electrode (RHE), from which the coverage of the Co-PP on the PG electrode can be determined to be ca. $4 \times 10^{-10} \mathrm{~mol} \mathrm{~cm}^{-2}$, which is in good agreement with previous experiments of protoporphyrins on $\mathrm{PG}^{19,21}$. No further redox transition of the CoPP is observed at more negative potential, with the onset of hydrogen evolution being at ca. $-0.5 \mathrm{~V}_{\mathrm{RHE}}$. However, we note that we have previously observed a $\mathrm{Co}^{2+} / \mathrm{Co}^{+}$transition at ca. $-0.6 \mathrm{~V}$ versus NHE for CoPP immobilized in a DDAB (didodecyl dimethylammonium bromide) film on $\mathrm{PG}^{19}$. The observation of this peak in the DDAB films may be related to the higher hydrophobicity of DDAB. The $\mathrm{Co}^{2+} / \mathrm{Co}^{+}$redox transition has previously been associated with the onset of electrocatalytic hydrogen evolution on Co porphyrins ${ }^{22}$.

Figure 1 shows the voltammetry at $1 \mathrm{mV} \mathrm{s}^{-1}$ of the CoPP-PG electrode in unbuffered $0.1 \mathrm{M}$ perchlorate solution of $\mathrm{pH}=1-3$, saturated with $\mathrm{CO}_{2}$, together with the mass signals corresponding to $\mathrm{H}_{2}(m / z=2), \mathrm{CH}_{4}\left(m / z=15\right.$, corresponding to the $\mathrm{CH}_{3}$ fragment) and $\mathrm{CO}(\mathrm{m} / \mathrm{z}=28)$ as measured simultaneously using online electrochemical mass spectrometry (OLEMS) ${ }^{23}$. The OLEMS experiment samples the gases formed at the electrode surface by a tip covered with a hydrophobic membrane placed at a distance of ca. $10 \mu \mathrm{m}$ from the surface. This technique can follow gas production online during cyclic voltammetry (CV). Calibration of our experiment is cumbersome as the signals depend on parameters that are not easy to control (tip distance and tip porosity). Quantitative measurements were therefore performed using long-term electrolysis combined with gas chromatography (to be discussed later). Depending on the quality of the gas-sensing tip used in the OLEMS experiment shown in Fig. $1, m / z=31$ was also measured, corresponding to the formation of methanol (Supplementary Fig. 2). Using highperformance liquid chromatography (HPLC), we could also detect $\mathrm{HCOOH}$ as one of the products (Supplementary Fig. 3), although both $\mathrm{HCOOH}$ and methanol appear to be minority products under these conditions. This confirms, for the first time in a single study, that all four products, $\mathrm{CO}, \mathrm{HCOOH}, \mathrm{CH}_{3} \mathrm{OH}$ and $\mathrm{CH}_{4}$ can be formed from $\mathrm{CO}_{2}$ reduction on a Co-based porphyrin. Figure $1 \mathrm{a}, \mathrm{d}, \mathrm{g}$ measured at $\mathrm{pH}=1$ shows that the 

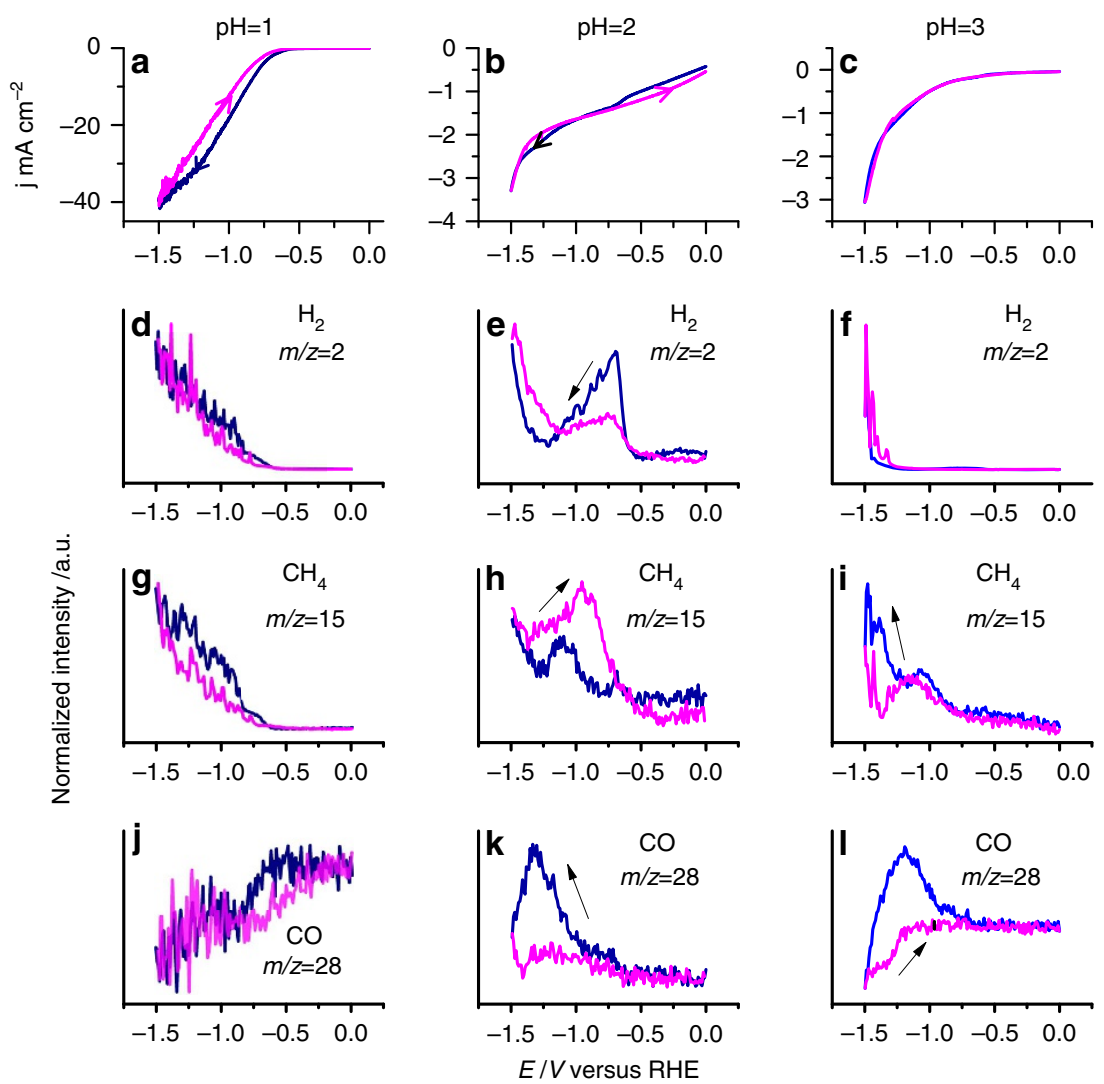

Figure 1 | Voltammetry and volatile product identification by online electrochemical mass spectrometry. This figure shows the electrochemical reduction of $\mathrm{CO}_{2}$ on Co protoporphyrin immobilized on a PG electrode and the various volatile products detected by OLEMS. (a) $\mathrm{CV}$ in $0.1 \mathrm{M} \mathrm{HCIO} 4$; (b) $\mathrm{CV}$ in $10 \mathrm{mM} \mathrm{HClO}_{4}+90 \mathrm{mM} \mathrm{NaClO}_{4} ;$ (c) $\mathrm{CV}$ in $1 \mathrm{mM} \mathrm{HClO}_{4}+99 \mathrm{mM} \mathrm{NaClO}_{4} ;$ (d) $\mathrm{m} / z=2\left(\mathrm{H}_{2}\right)$ signal in $0.1 \mathrm{M} \mathrm{HClO}_{4} ;(\mathbf{e}) \mathrm{m} / z=2\left(\mathrm{H}_{2}\right)$ signal in $10 \mathrm{mM}$ $\mathrm{HClO}_{4}+90 \mathrm{mM} \mathrm{NaClO}_{4} ;(\mathbf{f}) \mathrm{m} / z=2\left(\mathrm{H}_{2}\right)$ signal in $1 \mathrm{mM} \mathrm{HClO}_{4}+99 \mathrm{mM} \mathrm{NaClO}_{4} ;(\mathbf{g}) \mathrm{m} / z=15\left(\mathrm{CH}_{4}\right)$ signal in $0.1 \mathrm{M} \mathrm{HClO} 4 ;(\mathbf{h}) \mathrm{m} / z=15\left(\mathrm{CH}_{4}\right)$ signal in $10 \mathrm{mM} \mathrm{HClO}_{4}+90 \mathrm{mM} \mathrm{NaClO}_{4} ;(\mathbf{i}) \mathrm{m} / z=15\left(\mathrm{CH}_{4}\right)$ signal in $1 \mathrm{mM} \mathrm{HClO}_{4}+99 \mathrm{mM} \mathrm{NaClO}$; $(\mathbf{j}) \mathrm{m} / z=28(\mathrm{CO})$ signal in $0.1 \mathrm{M} \mathrm{HClO}$; $(\mathbf{k}) \mathrm{m} / z=28$ (CO) signal in $10 \mathrm{mM} \mathrm{HClO}_{4}+90 \mathrm{mM} \mathrm{NaClO}_{4} ;(\mathbf{I}) \mathrm{m} / z=28(\mathrm{CO})$ signal in $1 \mathrm{mM} \mathrm{HClO}_{4}+99 \mathrm{mM} \mathrm{NaClO}_{4}$. Scan rate was in all cases $1 \mathrm{mVs}{ }^{-1}$. Blue lines are negative-going (forward) scans; magenta lines are positive-going (return) scans. Supplementary Fig. 4 shows the same data with the unnormalized MS signals, as well as the signals obtained in the first and second CV scan.

reduction current is accompanied by the simultaneous formation of $\mathrm{H}_{2}$ and $\mathrm{CH}_{4}$. The $m / z=28$ signal in Fig. 1 was not corrected for the $\mathrm{CO}_{2}$ fragmentation, and therefore the $\mathrm{CO}$ signal combines $\mathrm{CO}$ production from $\mathrm{CO}_{2}$ electroreduction with $\mathrm{CO}$ formation from $\mathrm{CO}_{2}$ fragmentation in the mass spectrometer (MS). This explains why the $\mathrm{CO}$ signal decreases for more negative potentials at which the $\mathrm{CO}_{2}$ reduction rate is higher, as a result of the lower local $\mathrm{CO}_{2}$ concentration near the electrode surface. However, at $\mathrm{pH}=2$ and 3 , an increase in the $\mathrm{CO}$ signal with more negative potential is observed, simultaneously with the $\mathrm{CH}_{4}$ production, suggesting that $\mathrm{CO}$ is an intermediate in the reaction (as also suggested by the fact that $\mathrm{CO}$ may be reduced to $\mathrm{CH}_{4}$ on CoPPPG; Fig. 4 below). Most significantly, at $\mathrm{pH}=3, \mathrm{CO}$ and $\mathrm{CH}_{4}$ production is observed at less-negative potentials than $\mathrm{H}_{2}$ evolution, showing that the $\mathrm{CO}_{2}$ reduction has a different $\mathrm{pH}$ dependence from the hydrogen evolution reaction. We chose to restrict ourselves to $\mathrm{pH} \leq 3$ in perchlorate solution in order to avoid the interference of buffering anions such as bicarbonate or phosphate (see below) with the $\mathrm{CO}_{2}$ reduction process.

We have performed a number of experiments to convince ourselves that the Co-PP is indeed the active catalytic centre turning over dissolved $\mathrm{CO}_{2}$. On the unmodified $\mathrm{PG}$ electrode and on a PG electrode modified with $\mathrm{Co}$-free protoporphyrin, $\mathrm{H}_{2}$ evolution was observed, but no $\mathrm{CO}_{2}$ reduction (Supplementary Figs 5 and 6). A PG electrode onto which a small amount of Co was electrodeposited was also tested for $\mathrm{CO}_{2}$ reduction, but showed no activity (Supplementary Fig. 7). Finally, the reduction of isotopically labelled ${ }^{13} \mathrm{CO}_{2}$ in deuterated water yielded $m / z=19$ (corresponding to ${ }^{13} \mathrm{CD}_{3}$ ) as reduction product (Supplementary Fig. 8), which irrefutably proves the reduction of dissolved $\mathrm{CO}_{2}$ into methane. These combined results show that the immobilized Co protoporphyrin is responsible for the production of $\mathrm{CO}$ and methane from $\mathrm{CO}_{2}$ electroreduction.

As mentioned, the most important conclusion from Fig. 1 is the remarkable role of the $\mathrm{pH}$. Initially, we performed the $\mathrm{CO}_{2}$ reduction experiments at $\mathrm{pH}=2$ and 3 in buffered phosphate solution, also yielding methane as a product but with a $\mathrm{pH}$ dependence that was not straightforward to understand. Therefore, we decided to remove the buffering phosphate anions, as they are suspected to interfere with the reactivity by coordinating to the catalytic centre ${ }^{24}$ or interacting with the catalytic intermediates. In non-adsorbing perchlorate solution, the role of the proton concentration can be better understood by comparing the voltammetry of the CoPP-PG in the absence of $\mathrm{CO}_{2}$ at $\mathrm{pH}=1-3$, as shown in Fig. 2. At $\mathrm{pH}=1$, there is only a single catalytic reduction wave in the potential window studied, corresponding to the reduction of $\mathrm{H}^{+}$to $\mathrm{H}_{2}$. The voltammetry at $\mathrm{pH}=2$ and 3 shows two waves, one at less-negative potential that is proportional to the $\mathrm{H}^{+}$concentration and corresponds to $\mathrm{H}^{+}$ reduction, and one starting at $-1.1 \mathrm{~V}$ that corresponds to $\mathrm{H}_{2} \mathrm{O}$ reduction. This is also reflected in the $\mathrm{H}_{2}$ formation profiles observed in the mass signals in Fig. 1. We must also take into 


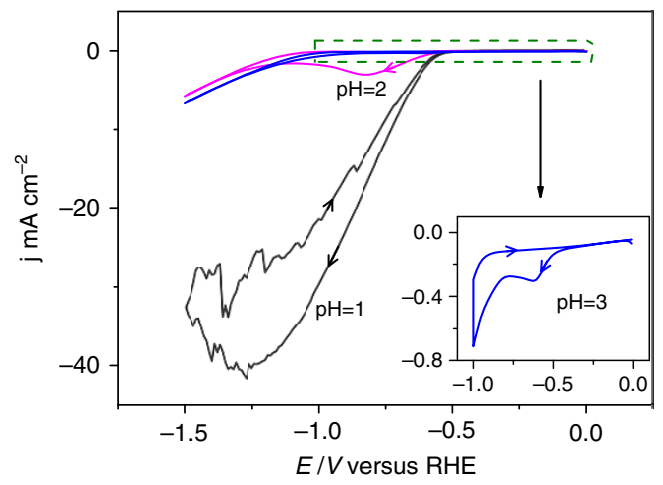

Figure $\mathbf{2}$ | $\mathbf{p H}$ dependence of hydrogen evolution reaction on the CoPP-PG electrode. Hydrogen evolution reaction at $\mathrm{pH}=1$ (black curve), $\mathrm{pH}=2$ (red curve) and $\mathrm{pH}=3$ (blue curve) on Co protoporphyrin-modified $\mathrm{PG}$ electrode in the absence of $\mathrm{CO}_{2}$. Inserted: highlight of the voltammetry at $\mathrm{pH}=3$. Scan rate was in all cases is $100 \mathrm{mVs}^{-1}$. All electrolyte solutions were $0.1 \mathrm{M}$ perchlorate, with different ratios of $\mathrm{H}^{+}$and $\mathrm{Na}^{+}$.

account here that because of the relatively low proton concentration at $\mathrm{pH}=3$, the direct proton reduction quickly runs into diffusion limitations, and further $\mathrm{H}_{2}$ evolution can only take place at more negative potentials by direct water reduction, which does not suffer from such diffusion limitations. By comparing the results in Figs 1 and 2, we conclude that $\mathrm{H}_{2}$ evolution dominates over $\mathrm{CO}_{2}$ reduction in the presence of a high concentration of protons in solution, whereas the opposite is the case for $\mathrm{pH}=3$. The activation of $\mathrm{CO}_{2}$ is apparently less sensitive to the presence of protons, implying that water molecules are just as powerful in hydrogenating the activated $\mathrm{CO}_{2}$. This remarkable $\mathrm{pH}$ dependence is somewhat similar to observations made by Noda et al. ${ }^{25}$ during $\mathrm{CO}_{2}$ reduction on a gold electrode. The important new finding here is that this small $\mathrm{pH}$ shift is the key in favouring $\mathrm{CO}_{2}$ reduction over $\mathrm{H}_{2}$ evolution, also on our molecular catalyst, especially in the absence of buffering anions. This is also evidenced by the FE measurements summarized in Fig. 3, to be discussed next. A mechanistic explanation for this $\mathrm{pH}$ sensitivity will be given in the Discussion section.

Faradaic efficiency. The FE for the simultaneous $\mathrm{CO}_{2}$ and water reduction to hydrogen, $\mathrm{CO}$ and methane was determined separately with long-term electrolysis experiments, using a gas chromatography setup coupled to an electrochemical cell, as detailed elsewhere ${ }^{26,27}$. Figure 3 shows results for $\mathrm{CO}$ and $\mathrm{CH}_{4}$ at $\mathrm{pH}=1$ and 3 for different potentials. The remaining current is used to form $\mathrm{H}_{2}$. The quantitative data and error bars are summarized and further explained in Supplementary Table $1 . \mathrm{HCOOH}$ was also observed as a minority product at $\mathrm{pH}=1$ using HPLC, but was not observed at $\mathrm{pH}=3$ (Supplementary Fig. 3). As mentioned above, methanol was observed as a product using OLEMS (Supplementary Fig. 2), but it remained below the detection limit during the gas chromatography (GC) measurements. At $\mathrm{pH}=1$, the $\mathrm{FE}$ to $\mathrm{CO}$ and methane is low, on the order of a per cent, and the dominant product is $\mathrm{H}_{2}$, and therefore for $\mathrm{pH}=1$, we show results at only a single potential in Fig. 3. Note, however, that at $\mathrm{pH}=1$, more methane is produced than $\mathrm{CO}$. At $\mathrm{pH}=3$, a dramatic change in selectivity is observed, with now $\mathrm{CO}$ being a majority product, especially at less cathodic potentials, for which the FE to $\mathrm{CO}$ is $\sim 40 \%$. This high selectivity is maintained for at least $1 \mathrm{~h}$ during the long-term electrolysis experiment at fixed potential (Supplementary Fig. 9), testifying to the good stability of the catalyst. The stability and integrity of the CoPP-PG electrode was also confirmed by pre- and postelectrolysis analysis using X-ray Photoelectron Spectroscopy

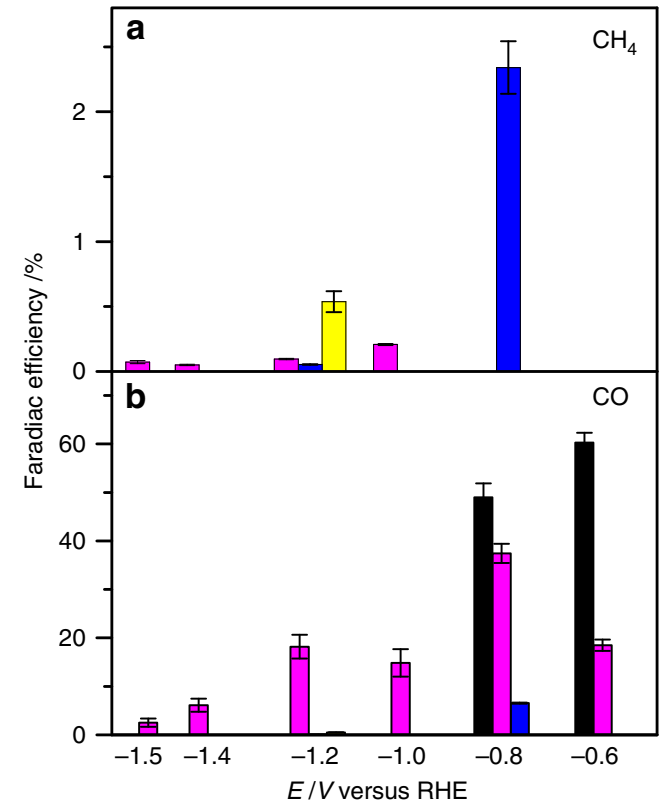

Figure 3 | FE of carbon dioxide reduction to $\mathbf{C O}$ and methane. FEs to $\mathrm{CO}$ and $\mathrm{CH}_{4}$ were determined for yellow bars: $\mathrm{pH}=1, P_{\mathrm{CO} 2}=1$ atm; blue bars: $\mathrm{pH}=1, P_{\mathrm{CO} 2}=10 \mathrm{~atm}$; magenta bars: $\mathrm{pH}=3, P_{\mathrm{CO} 2}=1 \mathrm{~atm}$ and black bars $\mathrm{pH}=3, P_{\mathrm{CO} 2}=10 \mathrm{~atm}$. $\mathrm{FE}$ of (a) $\mathrm{CH}_{4}$ and (b) $\mathrm{CO}$ in $0.1 \mathrm{M}$ perchlorate solution saturated with $\mathrm{CO}_{2}$. At each potential, the electrolysis was conducted for $1 \mathrm{~h}$ at $P_{\mathrm{CO} 2}=1 \mathrm{~atm}$, while it is $90 \mathrm{~min}$ at $P_{\mathrm{CO} 2}=10 \mathrm{~atm}$ due to the longer time to reach the steady state. Error bars were determined from 3-8 data points based on samples taken every 6 min during the steady state of a single electrolysis run.

(XPS), Raman and nuclear magnetic resonance (Supplementary Figs 10-12). Raman spectroscopy showed no significant change in the spectral features of the CoPP-PG surface; XPS showed no change in Co oxidation state after $1 \mathrm{~h}$ of electrolysis; and nuclear magnetic resonance showed no decomposition products in solution that could be related to CoPP. Figure 3 also illustrates that less methane is produced at $\mathrm{pH}=3$ as compared with $\mathrm{pH}=1$. We ascribe this lower methane production to the slower reduction of $\mathrm{CO}$ to $\mathrm{CH}_{4}$ at $\mathrm{pH}=3$ compared with $\mathrm{pH}=1$ (see next paragraph). The efficiency towards $\mathrm{CO}$ can be further boosted by performing the experiment at higher $\mathrm{CO}_{2}$ pressure. Figure 3 illustrates this for a $\mathrm{CO}_{2}$ pressure of $10 \mathrm{~atm}$, which leads to a $\mathrm{FE}$ of $\sim 60 \%$ at $\mathrm{pH}=3$ at a potential of $-0.6 \mathrm{~V}$. Note that at $\mathrm{pH}=1$, both the efficiency towards $\mathrm{CO}$ and $\mathrm{CH}_{4}$ increases to a few $\%$ when the reduction is carried out at increased $\mathrm{CO}_{2}$ pressure. We emphasize that OLEMS and GC experiments exhibited good consistency and reproducibility. The error bars shown in Fig. 3 were based on single long-term electrolysis experiments sampled every $6 \mathrm{~min}$.

Reduction of other compounds. To determine the involvement of potential intermediates, we also studied the reduction of $\mathrm{HCOOH}, \mathrm{CO}$ and formaldehyde ( $\mathrm{HCHO}$ ), by combined voltammetry-OLEMS. $\mathrm{HCOOH}$ was not reduced at either $\mathrm{pH}=1$ or 3 (Supplementary Fig. 13), and is therefore an end product, not an intermediate. Figure 4 shows the voltammetry and associated OLEMS mass signals on the CoPP-PG electrode for CO reduction at $\mathrm{pH}=1$ and 3 , and for $\mathrm{HCHO}$ reduction at $\mathrm{pH}=1$. Remarkably, $\mathrm{CO}$ is clearly reduced to methane at $\mathrm{pH}=1$, simultaneous with $\mathrm{H}_{2}$ evolution, but the $\mathrm{CO}$ reduction activity is much lower compared with hydrogen evolution at $\mathrm{pH}=3$, with an insignificant amount of $\mathrm{CH}_{4}$ detected. This observation is consistent with the results in Fig. 3, showing that methane production from $\mathrm{CO}_{2}$ 

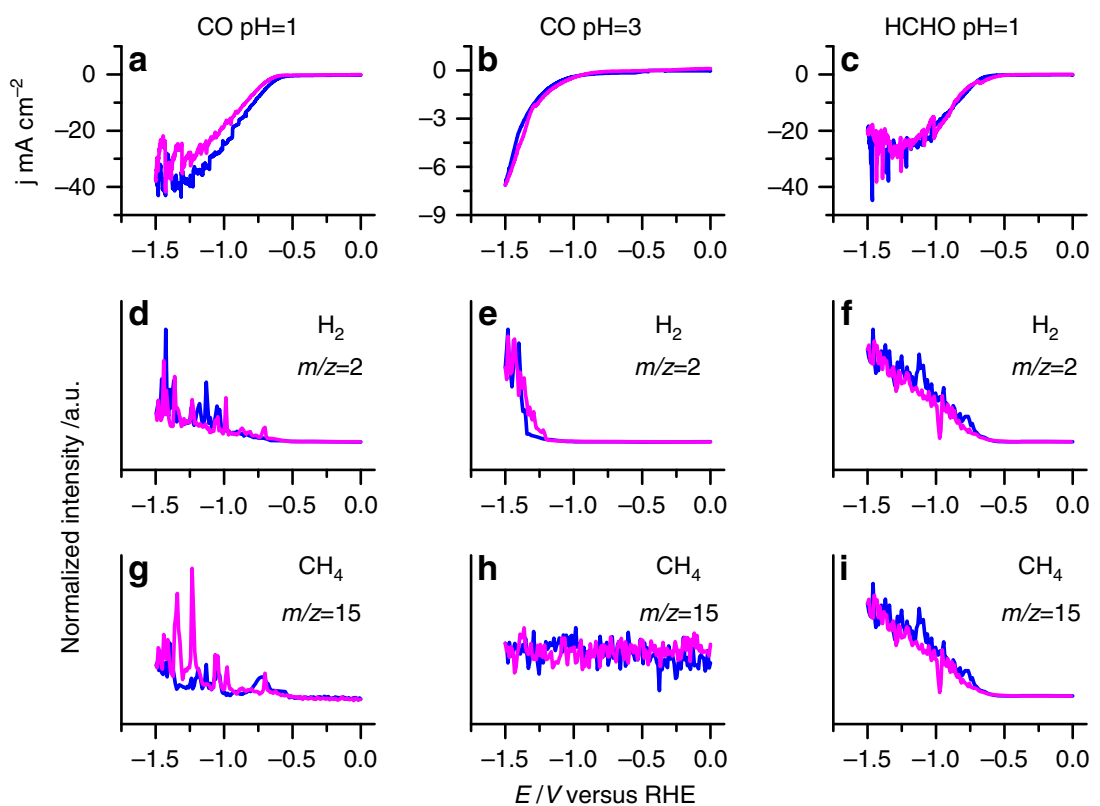

Figure 4 | Identification of volatile products by OLEMS during electrochemical reduction of $\mathbf{C O}$ and $\mathbf{H C H O}$. $\mathrm{CV}$ of $\mathrm{CO}$ reduction in (a) $100 \mathrm{mM} \mathrm{HClO} 4$ and (b) $1 \mathrm{mM} \mathrm{HClO}_{4}+99 \mathrm{mM} \mathrm{NaClO}_{4}$ saturated with $\mathrm{CO}$ with associated mass fragments of volatile products detected with OLEMS. (c) CV of $\mathrm{HCHO}$ $(5 \mathrm{mM})$ reduction in $100 \mathrm{mM} \mathrm{HClO}_{4}$ with associated mass fragments measured with OLEMS. (d-f) The corresponding OLEMS signals for $m / z=2\left(\mathrm{H}_{2}\right)$; (g-i) The corresponding OLEMS signals for $\mathrm{m} / z=15\left(\mathrm{CH}_{4}\right)$. Scan rate: $1 \mathrm{mV} \mathrm{s}{ }^{-1}$. Blue lines are negative-going (forward) scans; magenta lines are positivegoing (return) scans. Supplementary Fig. 14 shows the same data with the unnormalized MS signals, as well as the signals obtained in the first and second CV scan.

is lower at $\mathrm{pH}=3$. $\mathrm{HCHO}$ is reduced to methane at $\mathrm{pH}=1$ and 3 (Fig. 4 only shows $\mathrm{pH}=1$ ). Interestingly, $\mathrm{HCHO}$ is not reduced to significant amounts of methanol, whereas methanol is the product of $\mathrm{HCHO}$ reduction on copper electrodes ${ }^{6}$. Figure 4 suggests that $\mathrm{CO}$ and $\mathrm{HCHO}$, or their catalyst-bound derivatives, are intermediates in the reaction mechanism from $\mathrm{CO}_{2}$ to $\mathrm{CH}_{4}$, but $\mathrm{HCOOH}$ is not. It also shows that the reduction of $\mathrm{CO}$ exhibits a different $\mathrm{pH}$ dependence compared with $\mathrm{CO}_{2}$ reduction, explaining why the selectivity of $\mathrm{CO}_{2}$ towards $\mathrm{CO}$ increases with higher $\mathrm{pH}$, but the selectivity towards $\mathrm{CH}_{4}$ decreases with higher $\mathrm{pH}$.

\section{Discussion}

The results presented above give unique new insights into the mechanism of $\mathrm{CO}_{2}$ electroreduction on immobilized Co protoporphyrins, and the observed $\mathrm{pH}$ dependence reveals the important role of the initial electron transfer to $\mathrm{CO}_{2}$ in the overall mechanism as explained below, and as illustrated in our suggested mechanistic scheme in Fig. 5. At $\mathrm{pH}=1$, the dominant reaction is hydrogen evolution:

$$
2 \mathrm{H}^{+}+2 \mathrm{e}^{-} \rightarrow \mathrm{H}_{2}
$$

At $\mathrm{pH}=3$, the main origin of hydrogen evolution is direct water reduction:

$$
2 \mathrm{H}_{2} \mathrm{O}+2 \mathrm{e}^{-} \rightarrow \mathrm{H}_{2}+2 \mathrm{OH}^{-}
$$

with reaction 1 generating a smaller amount of $\mathrm{H}_{2}$ at less-negative potential due to diffusion limitations (Fig. 2). This observation is very similar to recent experiments on platinum electrodes ${ }^{28}$. The observation that $\mathrm{CO}_{2}$ reduction to $\mathrm{CO}$ becomes much more dominant at higher $\mathrm{pH}$, must mean that $\mathrm{CO}_{2}$ activation does not sensitively depend on the presence of protons, and hence must involve an intermediate that can easily react with water at any $\mathrm{pH}$. Such an intermediate is most likely a negatively charged Brønsted base, and the most obvious candidate for this intermediate is a

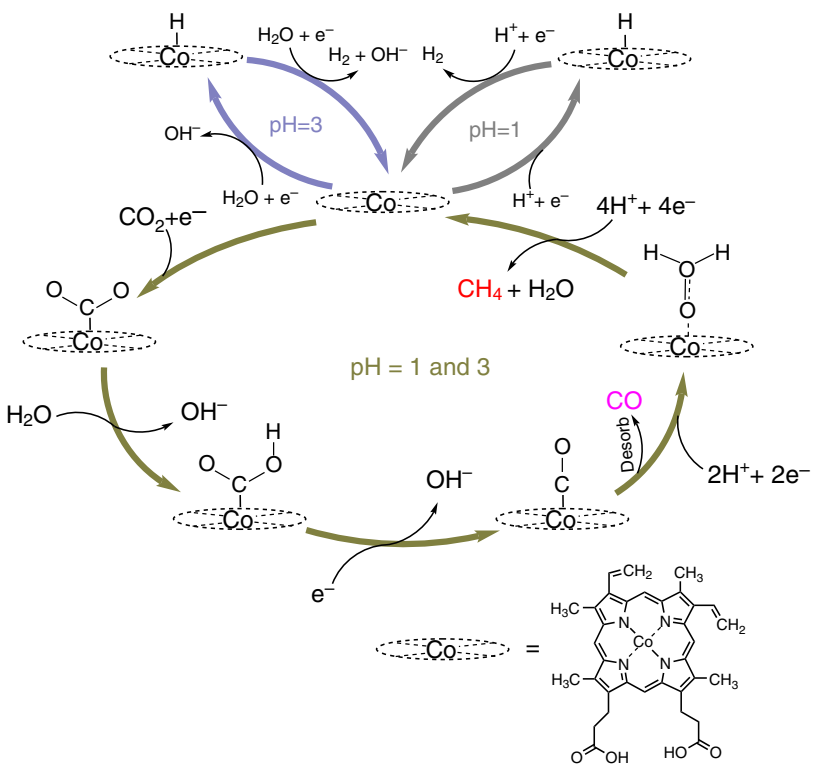

Figure 5 | Proposed mechanistic scheme for the electrochemical reduction of $\mathrm{CO}_{2}$ on Co protoporphyrin. $\mathrm{H}^{+}$and $\mathrm{H}_{2} \mathrm{O}$ are the hydrogen source for the hydrogen evolution reaction at $\mathrm{pH}=1$ and 3 , respectively. $\mathrm{CO}_{2}^{\bullet-}$ is the initial intermediate for the $\mathrm{CO}_{2}$ reduction to $\mathrm{CO}$. $\mathrm{CO}$ can be further reduced to methane with $\mathrm{HCHO}$ as an intermediate. The catalytically inactive 'resting' state of the $\mathrm{Co}$ is assumed to be $2+$. The reduction of $\mathrm{Co}^{2+}$ to $\mathrm{Co}^{+}$is supposed to trigger both the $\mathrm{H}_{2}$ evolution and $\mathrm{CO}_{2}$ reduction pathways.

$\mathrm{CO}_{2}$ radical anion ${ }^{25,29,30}$ bound to the Co complex ' $\mathrm{M}$ ':

$$
\mathrm{CO}_{2}+\mathrm{M}+\mathrm{e}^{-} \rightarrow \mathrm{M}-\left(\mathrm{CO}_{2}^{-}\right)
$$

which subsequently reacts with water to a metal-bound 
carboxyhydroxyl intermediate:

$$
\mathrm{M}-\left(\mathrm{CO}_{2}^{\bullet-}\right)+\mathrm{H}_{2} \mathrm{O} \rightarrow \mathrm{M}-\mathrm{COOH}+\mathrm{OH}^{-}
$$

The formation of the $\mathrm{CO}_{2}^{\bullet-}$ radical anion normally has a very negative redox potential ${ }^{3,8}$, but may be shifted to less-negative potential by the stabilization provided by the coordination of $\mathrm{CO}_{2}^{\bullet-}$ to the catalyst. The carboxyhydroxyl intermediate then generates $\mathrm{CO}$ :

$$
\mathrm{M}-\mathrm{COOH}+\mathrm{e}^{-} \rightarrow \mathrm{M}-\mathrm{CO}+\mathrm{OH}^{-}
$$

with the $\mathrm{CO}$ subsequently dissociating from the complex. Owing to the presence of the negatively charged intermediate in reaction 4 , the $\mathrm{pH}$ dependence of this pathway is different from that of the mechanism for reactions 1 and 2, in which no such intermediate is assumed. For reactions 1 and 2, we assume:

$$
\begin{gathered}
\mathrm{H}^{+}+\mathrm{M}+\mathrm{e}^{-} \rightarrow \mathrm{M}-\mathrm{H} \\
\mathrm{H}^{+}+\mathrm{M}-\mathrm{H}+\mathrm{e}^{-} \rightarrow \mathrm{H}_{2}+\mathrm{M}
\end{gathered}
$$

and

$$
\begin{gathered}
\mathrm{H}_{2} \mathrm{O}+\mathrm{M}+\mathrm{e}^{-} \rightarrow \mathrm{M}-\mathrm{H}+\mathrm{OH}^{-} \\
\mathrm{H}_{2} \mathrm{O}+\mathrm{M}-\mathrm{H}+\mathrm{e}^{-} \rightarrow \mathrm{H}_{2}+\mathrm{M}+\mathrm{OH}^{-}
\end{gathered}
$$

which involve concerted proton-coupled electron transfer at every step $^{31,32}$. Reaction 4 is different from the reaction suggested by the Density Functional Theory (DFT) calculations of Leung et al. ${ }^{29,30}$ because we specify that the proton donor may be water, rather than $\mathrm{H}^{+}$, owing to the basic character of the $\mathrm{CO}_{2}$ radical anion intermediate. Note that in this mechanism, the reaction rate for $\mathrm{CO}_{2}$ reduction itself does not depend on $\mathrm{pH}$, only its relative rate with respect to the hydrogen evolution. Another way of formulating our mechanism is by stating that in the potential window of interest, $\mathrm{CO}_{2}$ reduction is approximately zeroth order in proton concentration, while hydrogen evolution is first order in proton concentration.

The further reduction of $\mathrm{CO}$ must be slower than its generation, explaining the relatively low overall $\mathrm{FE}$ of $\mathrm{CO}_{2}$ reduction to methane. To explain the $\mathrm{pH}$ dependence of $\mathrm{CO}$ reduction and methane selectivity from $\mathrm{CO}_{2}$, we must assume that $\mathrm{CO}$ is reduced to methane without the involvement of negatively charged intermediates. Our experiments also show that an intermediate or by-product of $\mathrm{CO}$ reduction to methane is HCHO. Our suggested overall mechanism is summarized in Fig. 5.

The above mechanism, which we believe explains our observations consistently, has important implications for future catalyst design. The onset potential for $\mathrm{CO}_{2}$ reduction is determined by reaction 3 , that is, by the stabilization of the $\mathrm{CO}_{2}$ radical anion coordinated to the complex. As noted above, the onset potential appears to be related to the $\mathrm{Co}^{2+}$ / $\mathrm{Co}^{+}$redox transition on the basis of $\mathrm{CV}^{19}$ and also on the previous observation that the $\mathrm{Co}^{+}$state is the active state for proton reduction ${ }^{22}$. Nielsen and Leung have also concluded, based on literature data and their own DFT calculations, that $\mathrm{CO}_{2}$ binds to the $\mathrm{Co}^{+}$state of the porphyrin ${ }^{29,30}$. Therefore, we assume that $\mathrm{Co}^{+}$state of the CoPP is the catalytically active state. The closer the $\mathrm{Co}^{2+} / \mathrm{Co}^{+}$redox potential lies to the overall equilibrium potential, the lower is the overpotential for $\mathrm{CO}_{2}$ reduction. Reaction 3 is therefore the potential-determining step $^{33,34}$. The key point is that the formation of this intermediate is decoupled from proton transfer, as otherwise we cannot explain the observed $\mathrm{pH}$ dependence, an important feature not included in the recent DFT calculations of Tripkovic et al. ${ }^{9}$. Therefore, future calculations must take into account the existence of such intermediates, and should aim at enhancing the stability of the intermediate in reaction 3. Moreover, in order to have a higher overall efficiency towards methane, the rate of the reduction of $\mathrm{CO}$ to methane must be enhanced. Presumably, the rate of this reaction can be tuned by the binding of $\mathrm{CO}$ to the complex. This will also require further experiments and calculations aimed at screening various catalyst alternatives. We also believe that our mechanism provides a possible rationale for tuning the $\mathrm{H}_{2} / \mathrm{CO}$ ratio from electrochemical $\mathrm{CO}_{2}$ reduction, as was recently reported for a Ru-based molecular catalyst in aqueous solution ${ }^{35}$.

A final word on the overpotential and the TOFs of our catalyst in comparison with previous work on molecular catalysts for $\mathrm{CO}_{2}$ electroreduction to CO. From our experiment, we calculate TOFs through the formula: (FE for CO production) $\times($ current density $/ 2 F) /$ (number of Co-PP per $\mathrm{cm}^{2}$ ), where $F=$ Faraday constant. In Fig. 3, the average current densities measured over $1 \mathrm{~h}$ at potentials of -0.6 and $-0.8 \mathrm{~V}$ versus $\mathrm{RHE}$, corresponding to overpotentials of ca. 0.5 and $0.7 \mathrm{~V}$, were 0.08 and $0.16 \mathrm{~mA} \mathrm{~cm}^{-2}$ (at atmospheric pressure), respectively. This corresponds to TOFs of ca. 0.2 and $0.8 \mathrm{~s}^{-1}$. Costentin et al. ${ }^{10}$ have recently reported on the enhanced activity of a modified Fe tetraphenylporphyrin for $\mathrm{CO}_{2}$ reduction to $\mathrm{CO}$ in a mixed $\mathrm{DMF}$-water solvent. In their experiment, the porphyrin was in solution. Their measured current densities and corresponding effective $\mathrm{CO}_{2}$ turnover rates are very similar to ours, namely, $0.3 \mathrm{~mA} \mathrm{~cm}^{-2}$ (see Supplementary Fig. 5 in their paper) at a similar overpotential of ca. $0.5 \mathrm{~V}$. Note that this comparison does not take into account that the solubility of $\mathrm{CO}_{2}$ is considerably higher in DMF-water mixtures than in water ${ }^{36}$, thereby leading to correspondingly higher turnover rates in the DMF-water mixture. From a mathematical model for their reactive system including mass transport of the catalyst to the electrode surface, they report a catalytic TOF of ca. $3,000 \mathrm{~s}^{-1}$. This is a TOF of a homogeneous catalyst corrected for the slow mass transport in their system, and can therefore not be compared directly with the 'effective' TOF of our heterogeneous catalyst. However, from the similar real current densities at a similar overpotential, we believe that we can safely state that our immobilized catalyst system has a similar efficiency.

Summarizing, we have shown that a Co protoporphyrin immobilized on a PG electrode can reduce $\mathrm{CO}_{2}$ to $\mathrm{CO}$ and even to the 6- and 8-electron products methanol and methane, in a purely aqueous electrolyte phase, with a moderate overpotential of ca. $0.5 \mathrm{~V}$. The efficiency of our catalyst (that is, effective rate at given overpotential) compares favourably with best porphyrinbased catalyst reported in the literature ${ }^{10}$. For optimal FE, that is, low concomitant $\mathrm{H}_{2}$ production, the proton concentration needs to be suitably tuned to the $\mathrm{CO}_{2}$ concentration. The $\mathrm{pH}$-dependent activity and selectivity are explained by a mechanism in which the initial step of $\mathrm{CO}_{2}$ reduction leads to a catalyst-bound $\mathrm{CO}_{2}^{\bullet-}$ radical anion. This intermediate has a strong Brønsted-base character and can abstract a proton from water, thereby leading to an overall reactivity of the $\mathrm{CO}_{2}$ reduction whose $\mathrm{pH}$ dependence is substantially different from the competing $\mathrm{H}_{2}$ evolution. Lowering the potential for the formation of this catalyst-bound $\mathrm{CO}_{2}^{--}$radical anion is therefore the key to making a better catalyst with a lower overpotential, and a suitable adjustment of $\mathrm{pH}$ will contribute significantly to a high $\mathrm{FE}$ of such a catalyst. The further reduction of $\mathrm{CO}$ to methane and methanol is slow owing to the weak binding of $\mathrm{CO}$ to the catalyst, and owing to the fact that $\mathrm{CO}$ reduction prefers a more acidic environment. These new insights into the mechanism of $\mathrm{CO}_{2}$ reduction on immobilized molecular catalysts in aqueous solution provide important design rules for future catalyst improvement. 


\section{Methods}

Electrochemistry and chemicals. The experiments were performed on homemade PG electrodes (Carbone-Lorraine; diameter, $5 \mathrm{~mm}$ ). Before each experiment, the electrodes were polished using P500 and P1000 SiC sandpaper consecutively, and were ultrasonicated in ultrapure water (Milli-Q gradient A10 system, $18.2 \mathrm{M} \Omega \mathrm{cm}$ ) for $1 \mathrm{~min}$ and dried in a flow originating from compressed air. The electrodes were subsequently immersed in the Co protoporphyrin (Frontier Scientific) solution $(0.5 \mathrm{mM}$ in borate buffer) for $5 \mathrm{~min}$ to immobilize the protoporphyrin on the surface and rinsed with ultrapure water before the experiments. A one-compartment electrochemical cell was used, with a platinum flag as counter electrode and a RHE as a reference, to which all potentials in this work are referred. The reference electrode was separated from the working electrode compartment through a Luggin capillary. An Ivium potentiostat/galvanostat (IviumStat) was used for the electrochemical measurements. Solutions were prepared from $\mathrm{HClO}_{4}$ (Merck, 70\%), $\mathrm{NaClO}_{4}$ (Sigma-Aldrich, $\geq 98.0 \%$ ), $\mathrm{NaOH}$ (Sigma-Aldrich, 99.998\%), borate (Sigma-Aldrich) and ultrapure water. Argon (Hoekloos, purity grade 6.0) was purged though the solutions for $30 \mathrm{~min}$ before the experiment to remove dissolved oxygen. The reported current densities refer to the geometric surface area.

Online electrochemical mass spectrometry. The volatile products of the $\mathrm{CO}_{2}$ electrochemical reduction were detected using online electrochemical mass spectroscopy (OLEMS) with an evolution mass spectrometer system (European Spectrometry systems $\mathrm{Ltd})^{23}$. A porous Teflon tip (inner diameter, $0.5 \mathrm{~mm}$ ) with a pore size of $10-14 \mu \mathrm{m}$ was positioned close $(\sim 10 \mu \mathrm{m})$ to the centre of the electrode. Before the experiments, the tip was dipped into a $0.2-\mathrm{M} \mathrm{K}_{2} \mathrm{Cr}_{2} \mathrm{O}_{7}$ in $2 \mathrm{M} \mathrm{H}_{2} \mathrm{SO}_{4}$ solution for $15 \mathrm{~min}$ and rinsed with ultrapure water thoroughly. The gas products were collected through a polyether ether ketone (PEEK) capillary into the mass spectrometer. A 2,400-V secondary electron multiplier (SEM) voltage was applied for all the fragments except for hydrogen $(\mathrm{m} / z=2)$ which is $1,500 \mathrm{~V}$. The OLEMS measurement was conducted while $\mathrm{CV}$ was scanning from 0 to $-1.5 \mathrm{~V}$ and back at a scan rate of $1 \mathrm{mV} \mathrm{s}^{-1}$.

Gas chromatography. The quantitative measurements of the gas products were carried out using $\mathrm{GC}^{26,27}$. At atmospheric pressure, $\mathrm{CO}_{2}$ was continuously purged through a two-compartment flow cell with a volume of $12 \mathrm{ml}$ for each compartment at a rate of $5 \mathrm{ml} \mathrm{min}^{-1}$ for $30 \mathrm{~min}$ to saturate the electrolyte. The flow rate declined to $2 \mathrm{ml} \mathrm{min}^{-1}$ while a constant potential was applied for $1 \mathrm{~h}$. The reference electrode used here is a $\mathrm{Ag} / \mathrm{AgCl}$ electrode. The experiments at high $\mathrm{CO}_{2}$ pressure $(P=10 \mathrm{~atm})$ were conducted in a stainless-steel autoclave using a $\mathrm{Pt}$ mesh as a counter electrode, and a home-made $\mathrm{Ag} / \mathrm{AgCl}$ in $3 \mathrm{M} \mathrm{KCl}$ as a reference electrode. All potentials were scaled to RHE after the experiments for both atmospheric and high pressure, with $E($ versus $\mathrm{Ag} / \mathrm{AgCl})=E$ (versus $\mathrm{RHE})-0.197 \mathrm{~V}-\mathrm{pH} \times 0.059$. $\mathrm{CO}_{2}$ was continuously purged through the autoclave before and during the electrolysis with a flow rate of $50 \mathrm{ml} \mathrm{min}^{-1}$. The reactor effluent was sampled via GC once every $6 \mathrm{~min}$. $\mathrm{CO}, \mathrm{CO}_{2}, \mathrm{H}_{2}$ and hydrocarbons were simultaneously separated using two series columns in series (a ShinCarbon $2 \mathrm{~m}$ micropacked column and a Rtx-1 column). The quantitative analysis of the gas products was performed using a thermal conductivity detector $\left(\mathrm{H}_{2}\right.$ and $\left.\mathrm{CO}\right)$ and flame ionization detector (hydrocarbons).

Online HPLC. HPLC (Prominence HPLC, Shimadzu) was used to detect liquid products produced during electrochemical reduction of $\mathrm{CO}_{2}$ using a method described in previous work ${ }^{37}$. Samples were collected using a Teflon tip (inner diameter: $0.38 \mathrm{~mm}$ ) positioned $\sim 10 \mu \mathrm{m}$ from the centre of the electrode surface (diameter: $1 \mathrm{~cm}$ ). The sample volume collected was $60 \mu \mathrm{l}$ stored in a 96-well microtitre plate $(270 \mu \mathrm{l}$ per well, Screening Device b.v.) using an automatic fraction collector (FRC-10A, Shimadzu). The flow rate of the sample collection was adjusted to $60 \mu \mathrm{lmin}{ }^{-1}$ with a Shimadzu pump (LC-20AT). A linear sweep voltammogram was recorded while the sample was collecting at a scan rate of $1 \mathrm{mV} \mathrm{s}^{-1}$ from 0 to $-1.5 \mathrm{~V}$ versus RHE. The microtitre plate with collected samples was then placed in an auto-sampler (SIL-20A) holder and $30 \mu \mathrm{l}$ of sample was injected into an Aminex HPX 87-H (Bio-Rad) column. The eluent was diluted sulfuric acid $(5 \mathrm{mM})$ with a flow rate of $0.6 \mathrm{ml} \mathrm{min}^{-1}$. The temperature of column was maintained at $85^{\circ} \mathrm{C}$ using a column oven (CTO-20A) and the separated compounds were detected with a refractive index detector (RID-10A).

\section{References}

1. Costentin, C., Robert, M. \& Saveant, J.-M. Catalysis of the electrochemical reduction of carbon dioxide. Chem. Soc. Rev. 42, 2423-2436 (2013).

2. Qiao, J., Liu, Y., Hong, F. \& Zhang, J. A review of catalysts for the electroreduction of carbon dioxide to produce low-carbon fuels. Chem. Soc. Rev. 43, 631-675 (2014)

3. Hori, Y. in Modern Aspects of Electrochemistry Vol. 42 (eds Vayenas, C. G., White, R. E. \& Gambao-Aldaco, M. E.) 89-189 (Springer, New York, 2008).

4. Finn, C., Schnittger, S., Yellowlees, L. J. \& Love, J. B. Molecular approaches to the electrochemical reduction of carbon dioxide. Chem. Commun. 48, 1392-1399 (2012)
5. Koper, M. T. M. Thermodynamic theory of multi-electron transfer reactions: implications for electrocatalysis. J. Electroanal. Chem. 660, 254-260 (2011).

6. Schouten, K. J. P., Kwon, Y., van der Ham, C. J. M., Qin, Z. \& Koper, M. T. M. A new mechanism for the selectivity to $\mathrm{C} 1$ and $\mathrm{C} 2$ species in the electrochemical reduction of carbon dioxide on copper electrodes. Chem. Sci. 2, 1902-1909 (2011).

7. Li, C. W., Ciston, J. \& Kanan, M. W. Electroreduction of carbon monoxide to liquid fuel on oxide-derived nanocrystalline copper. Nature 508, 504-507 (2014).

8. Savéant, J.-M. Molecular catalysis of electrochemical reactions. mechanistic aspects. Chem. Rev. 108, 2348-2378 (2008).

9. Tripkovic, V. et al. Electrochemical $\mathrm{CO}_{2}$ and $\mathrm{CO}$ reduction on metalfunctionalized porphyrin-like graphene. J. Phys. Chem. C 117, 9187-9195 (2013).

10. Costentin, C., Drouet, S., Robert, M. \& Savéant, J.-M. A local proton source enhances $\mathrm{CO}_{2}$ electroreduction to $\mathrm{CO}$ by a molecular Fe catalyst. Science 338, 90-94 (2012)

11. Fisher, B. J. \& Eisenberg, R. Electrocatalytic reduction of carbon dioxide by using macrocycles of nickel and cobalt. J. Am. Chem. Soc. 102, 7361-7363 (1980).

12. Kapusta, S. \& Hackerman, N. Carbon dioxide reduction at a metal phthalocyanine catalyzed carbon electrode. J. Electrochem. Soc. 131, 1511-1514 (1984).

13. Furuya, N. \& Matsui, K. Electroreduction of carbon dioxide on gas-diffusion electrodes modified by metal phthalocyanines. J. Electroanal. Chem. Interfacial Electrochem. 271, 181-191 (1989).

14. Sonoyama, N., Kirii, M. \& Sakata, T. Electrochemical reduction of $\mathrm{CO} 2$ at metal-porphyrin supported gas diffusion electrodes under high pressure $\mathrm{CO} 2$ Electrochem. Commun. 1, 213-216 (1999).

15. Magdesieva, T. V., Yamamoto, T., Tryk, D. A. \& Fujishima, A. Electrochemical Reduction of $\mathrm{CO}_{2}$ with transition metal phthalocyanine and porphyrin complexes supported on activated carbon fibers. J. Electrochem. Soc. 149, D89-D95 (2002).

16. Atoguchi, T., Aramata, A., Kazusaka, A. \& Enyo, M. Cobalt(II)tetraphenylporphyrin-pyridine complex fixed on a glassy carbon electrode and its prominent catalytic activity for reduction of carbon dioxide. Chem. Commun. 3, 156-157 (1991)

17. Yoshida, T. et al. Selective electroacatalysis for $\mathrm{CO} 2$ reduction in the aqueous phase using cobalt phthalocyanine/poly-4-vinylpyridine modified electrodes. J. Electroanal. Chem. 385, 209-225 (1995).

18. Tanaka, H. \& Aramata, A. Aminopyridyl cation radical method for bridging between metal complex and glassy carbon: cobalt(II) tetraphenylporphyrin bonded on glassy carbon for enhancement of $\mathrm{CO} 2$ electroreduction. J. Electroanal. Chem. 437, 29-35 (1997).

19. de Groot, M. T. \& Koper, M. T. M. Redox transitions of chromium, manganese iron, cobalt and nickel protoporphyrins in aqueous solution. Phys. Chem. Chem. Phys. 10, 1023-1031 (2008)

20. Tao, N. J., Cardenas, G., Cunha, F. \& Shi, Z. In situ STM and AFM study of protoporphyrin and iron(III) and zinc(II) protoporphyrins adsorbed on graphite in aqueous solutions. Langmuir 11, 4445-4448 (1995).

21. de Groot, M. T., Merkx, M., Wonders, A. H. \& Koper, M. T. M. Electrochemical reduction of NO by hemin adsorbed at pyrolitic graphite. J. Am. Chem. Soc. 127, 7579-7586 (2005)

22. Kellett, R. M. \& Spiro, T. G. Cobalt porphyrin electrode films as hydrogen catalysts. Inorg. Chem. 24, 2378-2382 (1985).

23. Wonders, A. H., Housmans, T. H. M., Rosca, V. \& Koper, M. T. M. On-line mass spectrometry system for measurements at single-crystal electrodes in hanging meniscus configuration. J. Appl. Electrochem. 36, 1215-1221 (2006).

24. Diaz-Morales, O., Hersbach, T. J. P., Hetterscheid, D. G. H., Reek, J. N. H. \& Koper, M. T. M. Electrochemical and spectroelectrochemical characterization of an iridium-based molecular catalyst for water splitting: turnover frequencies, stability, and electrolyte effects. J. Am. Chem. Soc. 136, 10432-10439 (2014).

25. Noda, H., Ikeda, S., Yamamoto, A., Einaga, H. \& Ito, K. Kinetica of electrochemical redcution of carbon-dioxide on a gole electrode in phosphate buffer solutions. Bull. Chem. Soc. Jpn 68, 1889-1895 (1995).

26. Kas, R. et al. Electrochemical $\mathrm{CO}_{2}$ reduction on $\mathrm{Cu}_{2} \mathrm{O}$-derived coppe nanoparticles: controlling the catalytic selectivity of hydrocarbons. Phys. Chem Chem. Phys. 16, 12194-12201 (2014).

27. Kas, R., Kortlever, R., Yllmaz, H., Koper, M. T. M. \& Mul, G. Manipulating the hydrocarbon selectivity of copper nanoparticles in $\mathrm{CO}_{2}$ electroreduction by process conditions. ChemElectroChem. 2, 354-358 (2015).

28. Strmcnik, D. et al. Improving the hydrogen oxidation reaction rate by promotion of hydroxyl adsorption. Nat. Chem. 5, 300-306 (2013).

29. Leung, K., Nielsen, I. M. B., Sai, N., Medforth, C. \& Shelnutt, J. A. Cobalt - porphyrin catalyzed electrochemical reduction of carbon dioxide in water. 2. mechanism from first principles. J. Phys. Chem. A 114, 10174-10184 (2010). 
30. Nielsen, I. M. B. \& Leung, K. Cobalt - porphyrin catalyzed electrochemical reduction of carbon dioxide in water. 1. a density functional study of intermediates. J. Phys. Chem. A 114, 10166-10173 (2010).

31. Koper, M. T. M. Theory of the transition from sequential to concerted electrochemical proton-electron transfer. Phys. Chem. Chem. Phys. 15, 1399-1407 (2013).

32. Koper, M. T. M. Theory of multiple proton-electron transfer reactions and its implications for electrocatalysis. Chem. Sci. 4, 2710-2723 (2013).

33. Nørskov, J. K. et al. Origin of the overpotential for oxygen reduction at a fuel-cell cathode. J. Phys. Chem. B 108, 17886-17892 (2004).

34. Koper, M. M. Analysis of electrocatalytic reaction schemes: distinction between rate-determining and potential-determining steps. J. Solid State Electrochem. 17, 339-344 (2013).

35. Kang, P., Chen, Z., Nayak, A., Zhang, S. \& Meyer, T. J. Single catalyst electrocatalytic reduction of $\mathrm{CO} 2$ in water to $\mathrm{H} 2+\mathrm{CO}$ syngas mixtures with water oxidation to O2. Energ. Environ. Sci. 7, 4007-4012 (2014).

36. Jödecke, M., Pérez-Salado Kamps, Á. \& Maurer, G. An experimental investigation of the solubility of $\mathrm{CO} 2$ in (N,N-dimethylmethanamide + water). J. Chem. Eng. Data 57, 1249-1266 (2012).

37. Kwon, Y. \& Koper, M. T. M. Combining voltammetry with HPLC: application to electro-oxidation of glycerol. Anal. Chem. 82, 5420-5424 (2010).

\section{Acknowledgements}

J.S. acknowledges the award of a grant of the Chinese Scholarship Council. This work was financed in part by NanoNextNL, a micro and nanotechnology consortium of the Government of the Netherlands and 130 partners, by the BioSolar Cells open innovation consortium, supported by the Dutch Ministry of Economic Affairs, Agriculture and Innovation, and by The Netherlands Organization for Scientific Research (NWO).

\section{Author contributions}

J.S. performed all the electrochemistry, OLEMS, GC and HPLC experiments. R. Kortlever assisted in the HPLC, OLEMS and GC experiments. R. Kas assisted in the GC and XPS measurements. Y.Y.B. assisted in the HPLC and OLEMS experiments, specifically those detecting methanol. O.D.-M., and I.L.-Y. assisted in the electrochemistry experiments. Y.K. assisted in the HPLC experiments and K.J.P.S. assisted in the OLEMS experiments. G.M. provided access to the GC and XPS measurements. J.S. and M.T.M.K. interpreted data and co-wrote the manuscript; and all authors commented on the manuscript. M.T.M.K. conceived the idea.

\section{Additional information}

Supplementary Information accompanies this paper at http://www.nature.com/ naturecommunications

Competing financial interests: The authors declare no competing financial interests.

Reprints and permission information is available online at http://npg.nature.com/ reprintsandpermissions/

How to cite this article: Shen, J. et al. Electrocatalytic reduction of carbon dioxide to carbon monoxide and methane at an immobilized cobalt protoporphyrin. Nat. Commun. 6:8177 doi: 10.1038/ncomms9177 (2015).

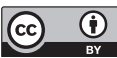
article are included in the article's Creative Commons license, unless indicated otherwise in the credit line; if the material is not included under the Creative Commons license, users will need to obtain permission from the license holder to reproduce the material. To view a copy of this license, visit http://creativecommons.org/licenses/by/4.0/ 